\title{
Opportunity to Transition with Dignity: Silos and Trialling in Aotearoa New Zealand
}

\author{
Sarah M. Hart \\ College of Education, Nursing, and Health Professions \\ University of Hartford \\ Janet S. Gaffney \\ Faculty of Education and Social Work \\ University of Auckland \\ Mary F. Hill \\ Faculty of Education and Social Work \\ University of Auckland
}

\begin{abstract}
Transition out of school is more than an administrative procedure, biological life stage, or public policy issue; transition is a human right. Yet, community participation in post-school life is challenging, particularly for those with significant disability. Findings from this 6-month ethnographic study confirm that two issues-silos, or breakdowns in collaboration, and trialling post-school options - were impediments to a transition with dignity. Deep examination into the experiences and perspectives of 3 young men demonstrated the challenges they faced in moving from schooling to life in the community. Their experiences were analyzed in a disability studies framework using the capability approach (Nussbaum, 2006; Sen, 1985) to prioritize opportunities to transition with dignity.
\end{abstract} Keywords: School leaving, significant disability, capability approach, inclusive human rights 


\section{Introduction}

For students with and without disabilities, transition out of school into young adulthood involves taking on new roles and adapting or changing existing roles (Osgood, Foster, Flanagan, $\&$ Ruth, 2005). Graduation from compulsory schooling is often synonymous with transition. Such a time can be marked by ending school, as well as a beginning of "active citizenship" (Smith, 2013, p. 415) that emphasizes community agency, individual autonomy, selfdetermination, and the right to participate in the social and economic life of the community. Community participation, then, is not only a goal, but a means to achieve social integration (Myers, Ager Kerr, \& Myles, 1998).

The focus here is on transition, or school leaving at the age of 21 years, for individuals with significant disabilities. In a medicalized sense, this label encapsulates a broad spectrum of low-incidence disabilities that have multiple and/or profound impacts upon cognitive, behavioral, health, and/or communicative abilities. The authors' conception of significant disability, however, is socially-oriented, noting ways that societal constructs can be more disabling than individual impairments (Albrecht, Seelman, \& Bury, 2001). The interactions within the meaning and nature of disability are critical and complex. The phrasing individuals with significant disabilities is used within this paper, however, we clarify our belief that disability doesn't exist simply within a person but within the mismatch and resulting needs for supports.

Active citizenship of individuals with significant disabilities following school depends as much upon in-school procedures and systems as it does the inclusivity of society itself. To illustrate, imagine that the intersections of freedom, choice, wellbeing, and dignity (Nussbaum, 2006) are upheld as integral components of transition. A young adult with significant disability might trial many different post-school options, maybe even consider attending university. Within these post-school options, "senses are used to imagine, think, and reason - and do these things in a 'truly human' way, a way informed and cultivated by an adequate education" (Nussbaum, 2000 , p. 78). Picture young adults having control over their future, where preferences for postschool life were actioned and they had "practical reason ... to engage in critical reflection about the planning of [their] own life" (Nussbaum, 2000, p. 78). Envision that community supports became places to "live with and toward others, to recognize and show concern for other humans, to engage in various forms of social interaction" (Nussbaum, 2000, p. 78). In all, imagine young adults with significant disabilities were "treated as a dignified being whose worth is equal to that 
of others" (Nussbaum, 2000, p. 78). These can be seen as the human rights of students with significant disabilities. One aim of the study reported here was to understand, from their perspectives as much as possible, the opportuinities three such students had to transition with diginity.

\section{Transition as a Human Right in Aotearoa New Zealand}

In Aotearoa ${ }^{i}$ New Zealand, practices to support transition for young adults with significant disabilities are in their infancy and have recently undergone pilot testing (Office of Disability Issues, 2015). The pilot was initiated by the Office of Disability Issues in 2011 after the country signed and ratified the United Nations Convention on the Rights of Persons with Disabilities (UNCRPD) on September 26, 2008. Within this human rights framework, emphasis is placed upon society's responsibility to expand the opportunities for life choices. Transition, therefore, serves to secure human rights such as personal control and freedom, seen here as components encapsulated by the term dignity.

The vision of a successful transition is to enable good lives. Individuals with disabilities should have personal choice and control over their lives and supports. Examples include selfdirected planning and facilitation of the process of school leaving, funding supports that cut across government sectors, individualization to strengthen families and whānau (extended family), and community building including natural supports (Enabling Good Lives, 2019).

Aligned with the human rights focus, transition from school for students with disability is understood less a "seamless" procedural exit from school (Certo, Luecking, Murphy, Brown, Courey, \& Belanger, 2008, p. 89), and more a social process. The end-game of this process is inclusion within society. Stated another way, transition is one aspect over the longer course of a successful and integrated life for individuals with disability.

Owing in part to current pilot testing, transition research in the country is sparse. In a participatory study conducted by those with and without disabilities about the transition experiences of young adults with disabilities, results of focus-group $(n=27)$ and questionnaire $(\mathrm{n}=81)$ data reported a desire to work, continue post-secondary study, and live outside the family home, but with limited ability to achieve these priorities (Dever, Gladstone, \& Quick, 2012). Note, however, this study was conducted only one year after the introduction of the transition pilot. In a policy review a few years later, Gladstone (2014) indicated that transition experiences 
for those with disabilities were akin to "supported loitering" (p. 230), due to unrealized goals and aspirations. Gladstone argued that young people with disabilities in Aotearoa New Zealand were the least likely of any marginalized group to be tertiary educated or employed, and this problem worsened the more severe the impairment.

Globally, two essential concerns exist regarding the procedures related to the transition from school for students with significant disabilities. First, students with significant disability experience dismal outcomes compared to their mainstream peers. "Youth with disabilities continue to face an uncertain future as they exit high school in spite of 25 years of transitionrelated legislation directed at improving post-high school outcomes for this population" (Rusch \& Wolfe, 2008, p. 96).

The second essential concern is individuals with significant disability have been alienated from their transition planning. Interviewed students expressed that they were rarely invited to transition planning meetings and, when invited, did not understand how to effectively contribute to the planning process (Hetherington, et al., 2010). The few students who managed to contribute felt that the transition goals did not match their personal objectives. While students' involvement in their transitions has been found to improve outcomes for youth with disabilities (Cobb \& Alwell, 2009), in a systematic review of 31 studies involving 859 youths with a wide variety of disabilities, student involvement was found challenging to achieve within the setting of Individualized Education Program (IEP) meetings (Martin, Van Dycke, Christensen, Greene, Gardner, \& Lovett, 2006). Adding to these concerns, across 764 IEP team members within 130 middle- and high-school transition IEP meetings, researchers found that "without specific IEP meeting instruction, students attending their meetings do not know what to do, do not understand the purpose or what is said, and feel as if none of the adult participants listen to them when they do talk" (Martin et al., 2006, p. 300). Lack of participation can eventuate in transition plans that are compliant with policy mandates, yet are evaluated to be of only adequate or minimal quality, due to vague goals that do not provide clear steps to facilitate students' successful entrance into their adult life (Grigal, Test, Beattie, \& Wood, 1997).

A key issue is that students, especially those with significant disabilities, are primarily defined by others by their deficits rather than their strengths (Carter, Boehm, Biggs, Annandale, Taylor, Lock, Liu, 2015). This is a significant concern during transition, a time where recognition of strengths is arguably needed for individuals to successfully engage in satisfying 
work and to engage meaningfully in the community. This article draws attention to this concern by focusing on what individuals with significant disabilities can do and who they want to be to articulate a transition with dignity. The capability approach was used to frame these ideas, interpret interactions and interviews, and formally evaluate, as well as attend to self-evaluations of individuals' dynamic abilities.

\section{Capability Approach}

The capability approach was developed as a broad, normative framework for welfare economics. It is used to focus attention to the wellbeing of every individual in their own right, regardless of ability or disability (Sen, 1985). A central distinction of the capability approach is the establishment of a life of personal value by way of (a) capabilities, what a person can do, be, and finds personally meaningful; (b) freedom, a person's actual opportunities to select from personally relevant opportunities that form an individual's capability set; and (c) functionings, the "beings and doings" (Sen, 1999, p. 6), the realized choices of a person's life. A novel way to examine individuals' exit from school to adult life is by defining transition as the way it expands an individual's capabilities (Hart, Gaffney, Hill, 2017).

Philosopher and legal scholar, Nussbaum (2000) worked from Sen's basic tenets of capability and identified 10 human capabilities to universalize fundamental human rights and principles that allowed for the greatest good for all human beings.

The capabilities approach operates with a list that is the same for all citizens, and it uses the notion of a threshold level of each of the capabilities, which is taken to be a minimum beneath which a decently dignified [emphasis added] life for citizens is not available.

(Nussbaum, 2006, p. 179)

For Nussbaum, human capabilities ensure all human beings have access to a life focused on thriving, not merely surviving. The central capabilities include life; bodily health; bodily integrity; senses, imagination, and thought; emotions; practical reason; affiliation; other species;

play; control over one's (political and material) environment (Nussbaum, 2000, p. 78). Nussbaum (2006) believed that each of the human capabilities must be met to a sufficient level — anything less was not a life as a "truly human being" (p. 78). Furthermore, dignity means not exchanging or replacing any of the 10 capabilities. Dignity is an interaction between an individual's freedom to choose from a personally meaningful capability set and societal contexts that promote such freedom. 
A capability approach was applied to this study in two ways. A disability-studies, socially-oriented conception of disability was used as a positional lens to view personal capabilities over disability. This interactional model (Mitra, 2006) enabled focus on the tensions that arise when reactions to disability, or focus on what a person cannot do, become more influential than what they can do. For example, a young adult's need for financial support to pay bills need not preclude their independent living and restrict opportunities to explore a range of housing options.

Secondly, a capability frame was used to examine the opportunity of dignity within transition. Priority was given to the conditions that preceded transition outcomes, regardless of how 'successful' they were deemed. For example, an individual in the study found his transition outcomes satisfactory despite that opportunities to explore a range of transition options were restricted. This limitation of possibilities impeded a dignified transition. Thus, the focus on capability and dignity did not mask or ignore challenges. This spirit is exemplified by others in Aotearoa New Zealand,

New Zealand, like many other countries in the world, is at the beginning of the journey, however, our walk is laboured as we try to carry with us the beliefs, values and assumptions based on exclusionary paradigms. These will wear us down and slow our passage unless they are recognized for what they are, challenged, and replaced by more inclusionary paradigms (Kearney \& Kane, 2006, p. 216).

In this spirit, the study reported in this article is part of the journey to replace the challenges of transition for individuals with significant disability with opportunities that are possible through dignity. The focus here was to consider other opportunities even when they did not occur in reality.

Guiding the study was the research question: how may understanding the perspective of individuals with significant disability impact a transition with dignity? Notably, the findings presented in this article provide a window into the social and interactional contexts that either help or hinder a transition with dignity. This is understood through an in-depth investigation of personal perspectives facilitated through the lived experiences of three 21-year old young men in their exit from school. 


\section{Method}

Data collection for this 6-month ethnographic study took place during the 3 months before and 3 months after school to post-school transition. A criterion for this study was to identify individuals who were in their final year of school and on the cusp of leaving school. The foremost commitment was to understand transition as it naturalistically progressed in a way that individuals with significant disability could contribute. A retrospective study, for example, would have precluded substantial contribution from those with significant disability as historical transition events may have been a struggle for them to meaningfully recall. Research progressed in-situ as the young men's transitions unfolded. Thus, it was not possible to know about the school, home, and community outcomes for the key participants until the transition unfolded, and the study was not contextually bound to one environment (e.g., a classroom, agency, or work setting).

\section{Setting}

Transition supports available to individuals with disabilities in Aotearoa New Zealand include academic, vocational, health, and social assistance. Exit from school marks a time when the need for social services, in particular for individuals with significant disabilities, will be reassessed to match the substantial changes in life circumstances. Within the education sector, students with significant disability are not required to have a specific disability label to receive special education services (Gaffney, Morton, \& Hart, 2017). Rather, students assessed as being within the highest $1 \%$ of significant need within the general student population have access to funding through the Ongoing Resource Scheme (ORS; Ministry of Education, 2016). ORS funding enables individualized modifications within mainstream schools or access to special education-focused special schools. The latter setting was selected as the starting point for this study to capture the experiences of those most significantly impacted by their disabilities.

\section{Central Participants}

School senior management within two urban special schools suggested the participation of three young men. Approval was granted to conduct the research by the University's Human Participants Ethics Committee (\# 9727) and legal consent was provided by all parents. Haku, Faine, and Cobain (all names are pseudonyms) were 21-year old young men exiting from secondary schooling after having extended time beyond 18 -years old to specifically focus on 
their transitions. Each young man had varying manifestations of autism-spectrum conditions (a label considered less stigmatizing as there are no demarcations between multiple conditions; Baron-Cohen et al., 2009). All three agreed to take part in the study and permitted access to their personal thoughts and transition experiences through substantial adaptations to the assent process to obtain the young men's informed assent to take part (Hart, Gaffney, \& Hill, 2017).

Haku and his mother were originally from Japan, having immigrated when he was a baby. He had attended special schools since his fifth birthday when children typically enter the education system. He was a mild-mannered young man who spoke verbally, yet for whom actions spoke louder than words. His preference was to work visually to offer his opinions and more complex ideas. Haku was interested in video games, and he participated in drama and dance. Haku transitioned out of a community-based classroom, situated in an office block where he could access a range of community services.

Faine was of indigenous Māori heritage. Before attending a special school for the last three years of his secondary education, Faine had attended a range of educational environments, including Māori medium education (aimed to revitalize Māori language, knowledge, and culture), and was also educated at home. Faine did not read or write, yet enjoyed using the computer to view pictures. He also enjoyed music and was very artistic in media such as drawing, painting, sculpture, and clothing design. He was the school's Māori cultural supervisor and a member of the school's rock band. Faine transitioned out of a community-based classroom situated in a storefront.

Cobain was Pākehāii ${ }^{\mathrm{ii}}$. He had attended special schools his whole educational career. Cobain had lived in residential care since age 10. Cobain did not speak verbally and his behaviors were unpredictable. Cobain enjoyed music, food, and sensory stimulations such as shadows, the noise from a dehumidifier, and crumpled paper. The class Cobain was attending in school was specifically for teenage and young adult students with high sensory needs.

Sixty transition informants also participated. The first author encountered these informants during the natural interactions in the fieldwork. All encounters were recorded as many individuals supplemented information and knowledge of the young men. They provided information about transition events (e.g., planning meetings) and background understanding about decisions made before the study through informal conversations, observations, and documentation shared with the researcher during the data-gathering phase. An interview was 
held with 10 transition informants who had a high degree of influence on transition decisions (e.g., parents, teachers, transition coordinators). Informants did not, however, provide proxy information on behalf of the young men, as has traditionally been the case in disability research (Carter, Brock, \& Trainor, 2014).

Key to the transition process in Aotearoa New Zealand is one calendar year of facilitated support to cross from school to post-school life. This facilitated support service is provided by specialists subcontracted by the Ministry of Social Development, referred to here as transition coordinators. Transition coordinators assist students with the most significant needs as denoted by access to ORS funds. Because the transition experience is unique for each student, goals are meant to be individual and transition planning a team process. Areas of planning include career planning, supported employment, life skills, further education, cultural support, access to community services (and necessary reassessments for funding), leisure and recreation activities, relationship building, and community access via transportation (Office for Disability Issues, 2016).

A central underlying assumption in this study was that the young men had the competence to contribute to both their own transition and this research. Ways to enable the young men's productive contributions were consistently sought through research partnerships forged between the first author, young men, and their transition informants (Hart, Gaffney, \& Hill, 2017).

\section{Data Collection Procedures}

Each young man's contribution to the research was consistently aligned with his capabilities, rather than with adapting ways for him to adhere to prescribed methodological formats. Adapted interviews were a cornerstone feature of the study. The young men expressed their perspectives through taking photographs, their artwork, and exchange of idiosyncratic artifacts that were uniquely memorable and symbolic of the transition process. For example, a surface understanding of each young man's timetable was an artifact that served as a organization tool. Investigated more deeply, however, each timetable reveled personal preferences essential to ensuring an individualized transition. Through adapted interviews, key transition events and settings were understood from the young men's perspectives. This was achieved in 13 interviews using seven adapted interview formats. Drawing from a qualitative toolkit (Kidney \& McDonald, 2014), individual adaptions were made, such as inviting the young 
men to use smartphones to collect audio and visual data akin to methods such as photo-voice (e.g., Wang \& Burris, 1997). Further detail can be found in Hart, Gaffney, \& Hill (2017). Where applicable, interviews were audio-recorded and transcribed. Where interviews were non-verbal, photographs and video were used to record their responses.

To further contextualize each transition, the following procedures were implemented: (a) observation of one activity (1-3 hours) per individual per week across six months, which totaled 103 hours across in-school (e.g., classroom, graduation, work experience) and post-school settings (e.g., community day programs, post-secondary education); (b) corresponding field notes $(n=46)$ were recorded immediately following each observation. Field notes included time and place descriptions, as well as noting who was involved in the event, activity, or observed context. Field notes were often supplemented with photographs and video, or informal conversations with the 60 informants; (c) Semi-structured interviews ( $\mathrm{n}=17$ ) with informants classified as having the highest influence upon transition decisions were conducted, audio-recorded, and transcribed; (d) artifacts $(\mathrm{n}=226$ ), including photographs, video, and documents were also collected in-school (e.g., school reports, behavior management plans) and post-school (e.g., funding applications, transition portfolios) environments. Also collected were non-traditional artifacts, such as Facebook posts, text messages, emails, and PowerPoint presentations. These artifacts were collected from the young men as well as their 60 informants.

\section{Analysis}

Thematic analysis was used to pinpoint, examine, and record patterns within the data (Braun \& Clarke, 2006). Figure 1 illustrates the stages of thematic analysis that were implemented. The first step was familiarity with the data. This came by organizing the data corpus through review of data logs (i.e., sequential notations of data collected during fieldwork) and memos (reflective notes recorded as the data was collected). In the second stage, NVivo software (2012) was used wherein nodes (i.e., collection of references about a specific theme, place, person or interest area, gathered by the coding of sources) were systematically parsed from each young man's data corpus. 


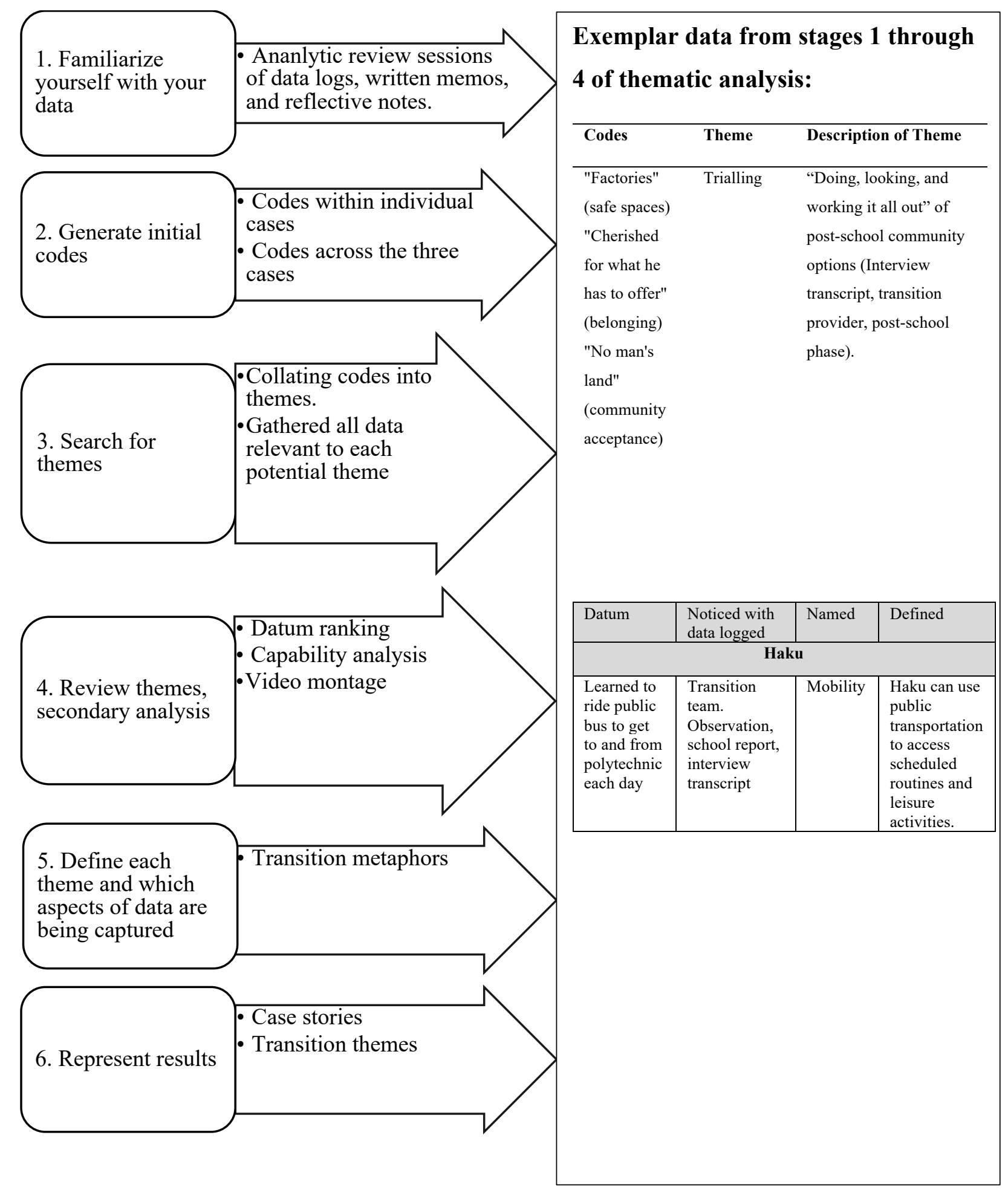

Figure 1. Thematic analysis model with stages of analysis and exemplar data. From "Using thematic analysis in psychology," by V. Braun \& V. Clarke, 2006, Qualitative Research in Psychology, 3(2), p. 87. Copyright 2006 by the American Psychological Association. 
The focus of this paper is on the emergent themes that arose from stage three of thematic analysis, also called "unanticipated insights" (Braun \& Clarke, 2006, p. 97). Silos and trialling were identified as critical themes because they significantly impacted the experiences of every young man in the study. Stage four involved the review of these two themes framed using the capability approach. Personal impacts of each theme were understood in stage five, by examination of transition experiences in light of personal capabilities. Every personal capability demonstrated by each young man during fieldwork was recorded including who noticed the capability. Table 1 includes excerpts from stage 6, capability-based case narratives written about each young man's transition.

Credibility measures were underscored by notions of researcher reflexivity (Brantlinger, et al., 2005). The first author was responsible for data collection and the second and third authors oversaw the conduct of the study and assisted with the trustworthiness of the data through coding checks throughout the design, execution, and analysis of the study. The second and third authors worked to ensure analytic procedures were not biased by the first researcher's perspectives and assumptions. Challenges to glean the young men's perspectives must not be overlooked. The positioning of the first author as both a deep insider, who was also accountable to bring interpretations to those less familiar, was especially important. Multiple data sources were vital to ensure rich, robust, and comprehensive interpretations were well-developed. Finally, prolonged field engagement provided repeated, substantive observations, including multiple, indepth interviews, and inspection of a range of relevant artifacts. Data-collection measures were recorded in an audit trail, documenting the chronology and the amount of time spent at each stage of fieldwork.

\section{Findings}

In this section, first-hand accounts are articulated in the vernacular used by those involved in transition, representative of the deep, rich engagement of ethnography. The case is made for two dominant and emergent findings of silos and trialling, which represent commonly shared experiences across the young men's transitions. These themes are brought forward to offer new considerations for transition practices. 


\section{Silos}

The term silos emerged during an interview with a transition coordinator. The transition coordinator described the challenges of working between the various government support agencies involved in transition,

There's a constant argument [about transition funding]. And at the end of the day, it all comes from the same purse [Collective taxpayer dollars], so the silo (emphasis added) aspect is frustrating.

In this context, a silo is a system, department, or individual that operates in isolation from others (Oxford English Dictionary, 2019). This definition aligns with the experiences expressed by the transition coordinator. Transition programs currently under pilot testing in Aotearoa New Zealand were designed to promote a partnership between government ministries and the disability sector. Therefore, the frustration expressed in the transition coordinator's quote about silos was initially surprising. To explore the concept further, analysis moved beyond the overt use of the term silo and explored wider instantiation of isolation and its opposite, collaboration.

One of the most significant silos occurred between the individuals involved in the transition planning team. While collaboration was expected, the consequences of silos were so significant that the teachers in all three cases were isolated from the transition processes and procedures of their students (Hart, Hill, \& Gaffney, 2015). Siloing also occurred at the systems level; between individuals and the social service systems designed to support them.

The first example of systems-level silos occurred between Haku and the Ministry of Social Development (MSD), specifically the branch of MSD responsible for providing financial

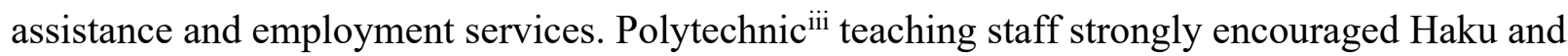
his mother to apply for discretionary funds for stationery and other school supplies to use in his polytechnic program. The application involved an interview meeting described using the field researcher's field notes,

After waiting for a half-hour to begin the appointment, we sat down at our meeting to learn from the social service officer that the meeting was booked too early before the course started. Haku's mother took this news politely. Her work colleague (whom Haku's mother had brought along for support) and I said nothing, but the frustration was palpable. Why could this "rule" not have been explained at the time of booking the appointment? And what kind of "rule" was it anyway? What was it trying to safeguard, 
other than increasing the likelihood that Haku and his mother would not return for another appointment? Frustratingly, the rescheduled appointment had to be made over the phone and would occur when Haku's mother was back to work, so she would need to take time off for the appointment.

Haku's example is illustrative of failure; whether it be of the policies themselves, the ability to adhere to them, or the flexibility of the system (and those who work within it) to accommodate people they intend to serve. Instead of social services working to understand and support Haku's needs, he was supposed to comply with their procedures. This example was emblematic of all the young men's experiences across all the support agencies related to transition. With every new support agency came another set of procedures to understand and to adhere.

A second example of silos provides a deeper understanding of the concept, as well as the personal impact. Faine's needs reassessment, related to services provided through a subcontracted service of Ministry of Health, was conducted by an assessor whom he had never met. The meeting was held at the Kura Kaupapa [Māori-language immersion] wing of the school where Faine's mother worked. Faine's mother, the transition coordinator, and the regional assessor were present. Despite this being a reassessment of Faine's needs, he was not present. His absence was, surprisingly, not questioned by the assessor. Faine's mother did not want her son to be present, for reasons soon evidenced.

The process of reassessment involved Faine's mother answering pre-set questions. The needs assessor recorded the answers by hand on triplicate carbon copies. Questions pertained to support networks - formal (e.g., school, Special Olympics), and informal (e.g., Faine's large whānau, extended family), - Faine's abilities in communication, mobility, and personal care. The comprehensive reassessment took two hours. After the assessor finished her questions and departed, a conversation between Faine's mother and the transition coordinator was recorded in the researcher's field notes,

Faine's mother says everyone in her family knows Faine is special but not because of his deficit needs, rather because of his abilities. "Besides, all this focus on the individual is so off from my way of thinking," said Faine's mother. "With my people, we move forward together. If one is held back, we are all held back." The overall tone was that the needs assessment and the individualist processes built into it could never take into account and 
appreciate the depth and complexity of Faine as a human being himself and his wider support networks.

To receive Ministry of Health funding, all individuals with significant disability must undergo assessment/reassessment processes such as the one experienced by Faine's mother. To access the required funding, Faine's mother was required to speak a language of pessimism and negativity. She needed to show deficits, which was uncomfortable for her to do. There was no space within this process for her to express her belief that it seemed the perceived good of society came before the welfare of the individual. Her son's identity was defined by problems and deficits, which led to increased funding. Faine's mother was aware that the needs reassessment would operate in this way and, therefore, didn't want her son present to hear the negative things being said about him. This glimpse into the needs-assessment process is a poignant example of the indignity families must endure to receive funding to support their child.

Elaborating further, Faine's mother essentially underwent this process alone, and was, hence, another silo. Although Faine's transition coordinator was present, she offered little more than moral support as she had met Faine and his mother only once before the meeting. No documentation, such as school reports, nor formal evaluations were referenced, all of which could have substantiated the claims being made about Faine's levels of functioning. Faine's mother was the sole advocate of her son's needs and experiences. The isolation of her experience established an undesirable silo whereby the reassessment process was based on her opinion of Faine's abilities, which informed a needs assessor who had never met her son. This lay in stark contrast to the traditional approach of Faine's family also observed in this study, in which the whānau (extended family) came together with Faine and his mother to provide support and make decisions collaboratively.

Since Cobain lived in residential care, the disability-care coordinator acted as an intermediary between Cobain's family and Ministry support services. The process to secure funding for Cobain, while not observed, would have been streamlined through direct communication between disability-care administration and social services. Cobain's experiences in residential care, therefore, represent another form of a silo. Opportunities to access activities outside those related to the disability-care service were isolated and restricted.

In each example, those involved acquiesced to funding-support systems that funneled them into a narrow set of procedures and processes framed by deficits, rather than a holistic 
consideration of transition supports across social services. Their capabilities were an afterthought within the assessment and transition process. Silos anonymized the young men, which led to transitions that emphasized compliance over personal preferences. These experiences comprised the context in which the next theme, trialling, was manifested.

\section{Trialling: The Trials of Transition}

To trial something is to test it for suitability. Trialling was an aspect of the transition process, a constituent feature of the four milestone stages of service provided by the transition coordinator. The first milestone was for the student in transition, their family, and school to select a transition coordinator from the available community options. A signed memorandum of understanding marked an agreement to begin the transition-coordination service. In the second milestone, the transition coordinator visited the school and family to construct a transition plan. The transition plan guided the services provided for students and their families. When asked what goes into the transition plan one transition provider replied, "What the young person wants to do, their dreams, their goals." When asked how transition coordinators ascertain such information, she replied,

Talking to them and everyone that's involved in their life. Like I'm doing home visits at the moment [and observing] IEP meetings at school. In certain situations, I've had to be involved with police safety teams or dual disability teams. All the variety of what's happening in a person's life. So as much as we can, we gather information, especially from the person. But if they're non-verbal, very high and complex needs, it's trying to glean what's them and what someone else thinks.

Trialling terminology is part of the final two milestone stages. Brokerage trialling, the exploration of post-school options, is the third milestone and the focus of this manuscript. Once transition options are selected, the fourth and final stage of outcomes trialling is a time for transitioning individuals to become acquainted with their selected post-school option.

Returning to the third stage, brokerage trialling involves the "doing, looking, and working it all out" of post-school community options (Transition coordinator). Notable for each young man were the types of options trialled, how and with whom such options were trialled, and the frameworks used to judge or assess each possible post-school option. To explore these aspects, the trials each young man was offered and experienced are described next. 
In reality, Haku did not have a brokerage trialling phase. He was shown only one postschool option, the polytechnic tertiary program in which he later enrolled. This program was specifically designed for individuals with disabilities to learn pre-employment skills in a segregated area of a mainstream campus. The following is an excerpt from an interview with the transition coordinator, and her colleague, in which she was asked why Haku explored only one option.

Transition coordinator: I've been doing it for many years. You sort of know. I mean, you know when you go in there to a day program, who's going to [tertiary] and who's not... Colleague: And the other thing about day programs is that a lot of them get very full very quickly. So, in some ways, we'd be wrong to take that place if the student we're working for is brighter. We should leave that place for someone who really needs it.

On paper, Haku's brokerage trialling was accomplished. Yet, he was not allowed to experience or consider a range of post-school options. In addition, Haku's transition coordinator was trusted to know what post-secondary option suited him best. In describing her focus for Haku's brokerage trialling, a tacit outcome of the transition from school service was revealed. Amongst finite post-school options and resources, spaces needed to be reserved "for someone who really needs it."

Faine's mother described her son's initial brokerage trialling at the same polytechnic in which Haku enrolled.

When we walked around, I didn't walk with him. I just wanted to see how he was. It was the first time I've seen him walk around and be confident. And go join in with people he didn't know. He was saying, 'come on [peers], come on let's go.'

The depiction of Faine's confidence and optimism and his mother's pride in describing her son's experiences created initial excitement to the trial of post-school options. At polytechnic, Faine's mother saw an environment where her son could focus on an academic trajectory. But Faine's mother also noted,

They didn't know that [Faine] can't read and he can't write. He was kinda faking that. $\mathrm{He}$ was going along with everybody. 
Faine's mother explained her assumption that her son's illiteracy would be an ongoing problem at a polytechnic, an assumption she did not, however, discuss with anyone on the transition planning team. Instead, Faine's mother simply did not pursue the polytechnic option and Faine's brokerage trialling continued.

The priority of Faine's brokerage trialling was to find a post-school option where he could be and feel productive and do more than "click time over" (Faine's mother). Second choice available options were less desirable to Faine as well as his family, with positive aspects having to be searched for, rather than weighted, compared, and considered. Amongst the second-best trialling options, the lack of communication (silo effect) meant the options best suiting his capabilities were not discussed. After transition, Faine attended an arts-focused day program. This suited his strong artistic abilities, but many peer attendees had more severe communication impairments. Faine's ability to socialize, both a personal priority and central human capability, had been overlooked.

Cobain might be considered one of those who "needed" other options. His brokerage trialling became synonymous with the post-secondary option his mother called "factories." The term was used to express her animosity towards day programs or adult day-service centers that provide a place for individuals with disabilities to engage in activities outside the home. Her opinion about 'factories' was always emotionally evocative and stated with conviction. She often suggested that she wanted to raise the issue with broadcast news sources. Her unremitting passion, reflected in almost every fieldwork conversation and observation, was akin to this comment:

I don't like those factories; I don't think our kids should be put in those factories. And with Cobain, I feel that he will be forgotten. He hasn't come 21 years of his life to end up in a bloody factory. I'm sorry. It's just not right. You wouldn't put your little kid into one of those places that they expect these guys to go to. Sorry, I'm getting emotional now. I understand that it's about the funding, but that's not where these guys should end up, in that setting.

Cobain's mother highlighted concerns about funding and safety. Despite her concerns, these day service 'factories' were the only brokerage trialling option she was offered. Cobain himself was not shown any options, each was considered without him present. Cobain's parents conducted brokerage trialling without their son and assessed each day program as a resounding 
failure. The process of brokerage trialling seemed to reaffirm her son's marginalized place in society.

The experiences of brokerage trialling can be best understood as missed opportunities. Each young man missed the chance to explore a range of post-school options during the critical life stage of transition. In turn, each missed the opportunity to be agentic in constructing his future and setting priorities for an enjoyable and productive life post-secondary school.

\section{Discussion}

The silos and trials experienced by the young men were hurdles to overcome. Silos distanced the active engagement of each young man within his transition. For example, the divergent procedures between social service agencies overwhelmed Haku's transition processes, such that a limited number of post-school options were trialled. He and the other young men's experiences with silos and trialling countered the notion that transition within Aotearoa New Zealand is a passage from school into an inclusive society (Office for Disability Issues, 2015). Transition became a time where the young men and their families had to navigate discrete social services and comply with policies and procedures.

The transition coordinator served as a guide to each service's discrete applications and processes that had to be adhered to receive transition services. The role of the transition coordinator was restricted, however, as they were employed under the Ministry of Social Development, rather than the Ministry of Health, which is the primary fund holder following school. Lastly, interpersonal silos caused teachers to be absent from the planning and processes of their students' transitions (Hart, Hill, \& Gaffney, 2015). Teachers took a back seat to the transition coordinators.

Trialling was intended to include processes that got to know the student and family to explore post-secondary options with them. Once a post-school option was selected, trialling additionally entailed the handover process for the young adult to get to know the new staff, routines, and so forth. While the "doing, looking, and working it all out" of trialling should have led to a collaborative, decision-making process, in fact, none of the brokerage trialling experiences represented choices. The trialling experienced by the young men was one of a selffulfilling prophecy characterized, from a capability perspective, as adaptive preferences (Nussbaum, 2000). The young men's post-school options were limited because that was precisely 
what they were expected to be. These current realities are shaped by relational histories of lowexpectations and indignity for individuals with disability (Erevelles, 2011). For instance, Faine's mother chose, without consultation, to restrict her son's post-school options due to her concerns about his inability to read and write. His mother preferred not to consider post-secondary polytechnic education because her expectations, substantiated or not, were that modifications to the program would be unachievable. In this study, adapted preferences meant not considering all transition options. With restricted communication and absence of the teachers from the process, no one advocated to widen Faine's opportunities and adapt preferences to Faine's capabilities.

A slightly more optimistic take on trialling was that outcomes were generic. Findings from this study match earlier investigations, where vague transition outcomes have been noted in IEPs (Grigal, Test, Beattie, \& Wood, 1997). In the current study, the young men were understood by transition coordinators just enough to know which disability-specific, prestructured program they believed each suited. Silos meant that no one had the opportunity to effect a change to this approach. Cobain's case is a poignant example. With no pre-structured program considered sufficient, only 10 hours of individualized community engagement was allotted. Within this limited time per week, activities for him to engage in the community were difficult to find and action. In all, the ineffective trialling processes constrained the young men's exploration and establishment of their post-school priorities.

This research highlights another shortcoming of the young men's experiences, the insufficient attention paid to the range of experiences that informed individual preferences. For those with significant disabilities, additional attention must be placed upon the collaborative (or lack of siloed) perspectives that inform transition decision making. Simply said, emphasis needs to be on process rather than product, or in capability terms, on opportunities that transition opens rather than outcomes from the process (Sen, 1985).

While all three of the young men went on to post-school activities beyond, "supported loitering" in the community (Gladstone, 2014), only Haku achieved his personal aims, with the caveat that he was not aware of any other options. Findings from this study contribute to wider research concerns that more must be done to understand the strengths (Carter et al., 2015) of individuals with significant disabilities, and to build upon those strengths to be an active member/contributor of one's own transition team (Hetherington, et al., 2010). These practices can then preface opportunities to engage in inclusive post-school life and early adulthood. 


\section{Implications}

Capability is used to envision what structural, political, and economic conditions are needed to promote young adults to enjoy their rights as articulated in the UNCRPD (2007). In Figure 2, the undignified transition aspects of silos and trialling experienced by the young men are noted on the left-hand side. Each letter (A, B, C) denotes a pre-existing transition option. Within this undignified process, transition coordinators screened each young man to see which environment was the best match. Transition was procedurally completed, though not the preface to a thriving post-school life.
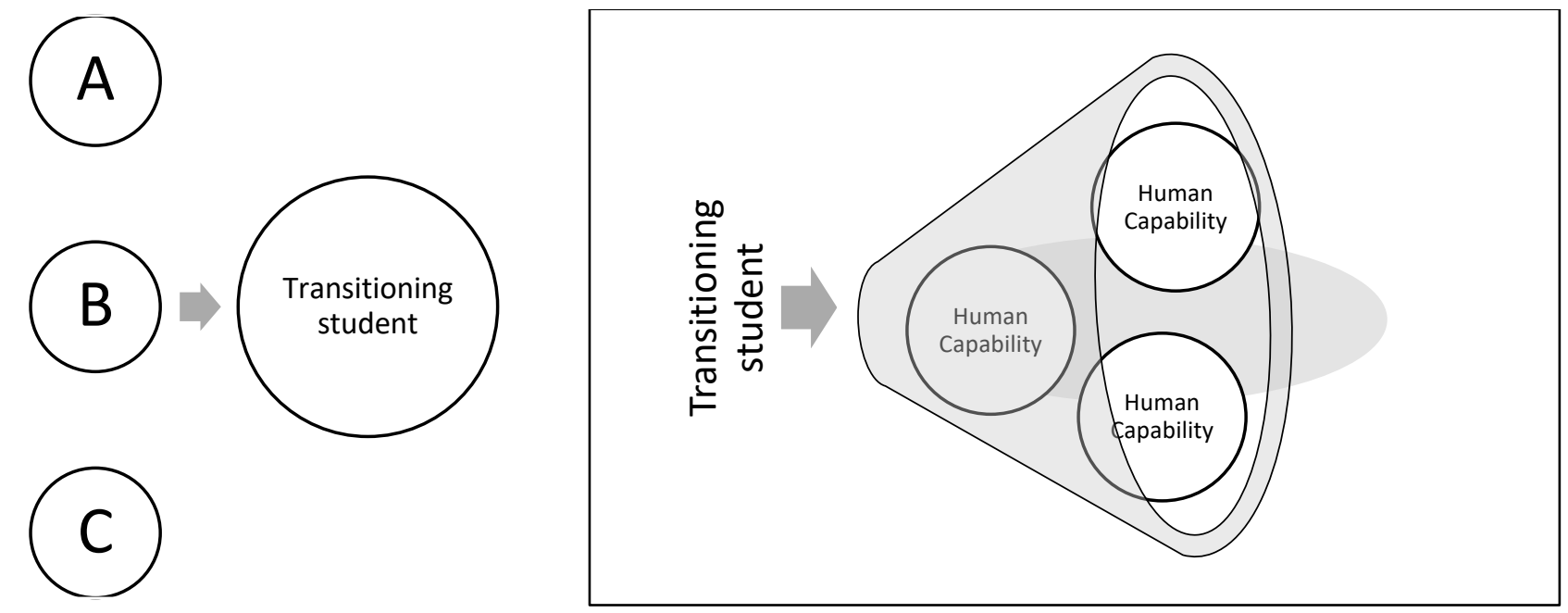

Figure 2. Undignified trialling (left) and trialling with dignity (right)

The right-hand side of Figure 2 demonstrates how transition could be informed by capability. By considering each of the 10 human capabilities as fundamental tenants of a good life (Nussbaum, 2000), the modified conception of trialling places emphasis on transition exploration before life outcomes. Personalized trialling would therefore involve expanding an individual's capability set by ensuring thorough exploration of viable opportunities. For instance, within the capability of emotions, transition providers would be responsible to address fundamental needs of socialization and fostering relationships, over, in Cobain's instance, attending a day service 'factory'.

\section{Limitations}

As a theoretical framework, the intentionally under-specified nature of capability as an approach rather than a theory challenges operationalization in research (Robeyns, 2006). 
Capability remains intentionally broad, despite the numerous and growing applications (e.g., education, Robeyns, 2006; development project evaluation, Alkire, 2002; quality of life indicators for individuals with disabilities, Brown, Hatton, \& Emerson, 2013). Within the scope of qualitative special-education research, theoretical grounding has been celebrated, however, for enhancing the researcher's "scholarly gaze" (Brantlinger, Jimenez, Klingner, Pugach, Richardson, 2005, p. 198). This study has further contributed to the application of capability as to improve life outcomes.

The sampling strategy used in this study prioritized access to in-depth and in-situ investigation. Identification of the three young men was opportunistic, following leads provided by senior management of identified schools, which inevitably influenced the overall findings. Future research should consider a wider range of schools, settings, and potentially, other countries. Lastly, the individual experiences of each young man are, admittedly distant within a paper on systemic and contextual impacts to a transition with dignity. A close focus on the personal journeys of each young man and elaboration of research methods are available in other publications (Hart, Gaffney, \& Hill, 2017; Hart, Hill, \& Gaffney, 2015).

\section{Conclusion}

The capability approach and human rights protections within the UNCRPD weave together the opportunity for exciting and engaging futures. Yet, findings of trialling and silos caution that awareness is needed to the misalignment between policy and practice. This paper focuses on transition as a human right that young people with disabilities are not always granted due to silos and trialling that are two challenges to transitioning with dignity. Necessary action is needed to address the silos of social supports and to expand and envision policy on trialling that truly captures individual capability sets. The human rights of young people with significant disabilities remain under-served until these key issues are addressed. Once understood, practices within Aotearoa New Zealand can extend globally to articulate and promote viable opportunities to transition with dignity.

"Just by being human, all are of equal dignity and worth, no matter where they are situated in society, and the primary source of this worth is a power of moral choice within them, a power that consists in the ability to plan a life in accordance with one's own evaluation of ends" (Nussbaum, 2006, p. 57). The realities of isolated silos of planning and fragmented 
trialling of post-school options can be reconsidered through a lens of capability. The time has come to recognize the inherent diversity in the disability experience and reclaim the rights of individuals with significant disabilities. Problems must make way for opportunities to see transition in new ways. In this manner, research conducted in Aotearoa New Zealand might be one way for the international community to literally see the topic of transition upside down.

\section{Notes}

iMāori terms and country name are used unless describing a specific document or agency. ii Māori term for someone of White, European descent.

iii Polytechnics are tertiary institutions, some of which offer transition to work programs for students with disabilities.

\section{References}

Albrecht, G. L., Seelman, K. D., \& Bury, M. (2001). Handbook of disability studies. Thousand Oaks, CA: Sage Publications.

Alkire, S. (2002). Dimensions of human development. World Development, 30(2), 181-205. doi:10.1016/S0305-750X(01)00109-7

Hart, S.M., Hill, M.F., \& Gaffney, J. S. (2015). Teachers absent: Impacts upon the transition of students with significant special needs. In D. Garbett \& A. Ovens (Eds.), Teaching for Tomorrow Today (pp. 491-498). Auckland: Edify.

Hart, S.M., Gaffney, J.S., \& Hill, M.F. (2017). Critical reflections on emancipatory partnerships in transition research: The process of discerning personal perspectives of young men on the autism spectrum in New Zealand. Disability \& Society. 23(6), 831-852. DOI: $10.1080 / 09687599.2017 .1329710$

Baron-Cohen, S., Scott, F. J., Allison, C., Williams, J., Bolton, P., Matthews, F. E., \& Brayne, C. (2009). Prevalence of autism-spectrum conditions: UK school-based population study. The British Journal of Psychiatry, 194(6), 500-509. doi:10.1192/bjp.bp.108.059345

Block, P. (2006). Community: The power of belonging. San Francisco: CA. Berret-Koehler Publishers. 
Brantlinger, E., Jimenez, R., Klingner, J., Pugach, M., \& Richardson, V. (2005). Qualitative studies in special education. Exceptional Children, 71(2), 195-207. doi:10.1177/001440290507100205

Braun, V., \& Clarke, V. (2006). Using thematic analysis in psychology. Qualitative Research in Psychology, 3(2), 77-101. doi:10.1191/1478088706qp063oa

Brown, I., Hatton, C., \& Emerson, E. (2013). Quality of life indicators for individuals with intellectual disabilities: Extending current practice. Intellectual and Developmental Disabilities, 51(5), 316-332. doi:10.1352/1934-9556-51.5.316

Carter, E. W., Boehm, T. L., Biggs, E. E., Annandale, N. H., Taylor, C. E., Loock, A. K., \& Liu, R. Y. (2015). Known for my strengths: Positive traits of transition-age youth with intellectual disability and/or autism. Research and Practice for Persons with Severe Disabilities, 40(2), 101-119. doi: 10.1177/1540796915592158

Carter, E. W., Brock, M. E., \& Trainor, A. A. (2014). Transition assessment and planning for youth with severe intellectual and developmental disabilities. The Journal of Special Education, 47(4), 245-255. doi:10.1177/0022466912456241

Certo, N. J., Luecking, R. G., Murphy, S., Brown, L., Courey, S., \& Belanger, D. (2008). Seamless transition and long-term support for individuals with severe intellectual disabilities.

Research and Practice for Persons with Severe Disabilities, 33(3), 85-95. doi:10.2511/rpsd.33.3.85

Cobb, R. B., \& Alwell, M. (2009). Transition planning/coordinating interventions for youth with disabilities: A systematic review. Career Development for Exceptional Individuals, 32(2), 70-81. doi:10.1177/0885728809336655

Dever, A., Gladstone, C., \& Quick, C. (2012). My life when I leave school: Transition project. Presentation of findings to the Honorable Tariana Turia, Minister for Disability Issues.

Devlieger, P. J., \& Trach, J. S. (1999). Mediation as a transition process: The impact on postschool employment outcomes. Exceptional Children, 65(4), 507-523.

doi:10.1177/001440299906500406

Enabling Good Lives. (2019). Enabling Good Lives Approach. Retrieved from: http://www.enablinggoodlives.co.nz

Erevelles, N. (2011). Disability and difference in global contexts: Enabling a transformative body politic. Berlin, Germany: Springer. 
Gaffney, J.S., Morton, M., \& Hart, S.M. (2017). Aotearoa New Zealand. In J. Patton \& M.

Wehmeyer (Eds.), Handbook of International Special Education (Volume 3). Santa Barbara, CA: ABC-CLIO.

Gladstone, C. (2014). Tales from the market. In R. Wills, M. Morton, M. McLean, M. Stephenson, \& R. Slee (Eds.), Tales from school: Learning disability and state education after administrative reform (pp. 227-237). Rotterdam, The Netherlands: Sense.

Grigal, M., Test, D. W., Beattie, J., \& Wood, W. M. (1997). An evaluation of transition components of individualized education programs. Exceptional Children, 63(3), 357-372. doi:10.1177/001440299706300305

Hetherington, S. A., Durant-Jones, L., Johnson, K., Nolan, K., Smith, E., Taylor-Brown, S., \& Tuttle, J. (2010). The lived experiences of adolescents with disabilities and their parents in transition planning. Focus on Autism and Other Developmental Disabilities, 25(3), 163-172. doi: $10.1177 / 1088357610373760$

Johnson, D. R., Stodden, R. A., Emanuel, E. J., Luecking, R., \& Mack, M. (2002). Current challenges facing secondary education and transition services: What research tells us. Exceptional Children, 68(4), 519-531. doi: 10.1177/001440290206800407

Kearney, A., \& Kane, R. (2006). Inclusive education policy in New Zealand: Reality or ruse? International Journal of Inclusive Education, 10(02-03), 201-219. doi:10.1080/13603110500256145

Kidney, C. A., \& McDonald, K. E. (2014). A toolkit for accessible and respectful engagement in research. Disability \& Society, 29(7), 1013-1030. doi:10.1080/09687599.2014.902357

Kim, K., \& Turnbull, A. P. (2004). Transition to adulthood for students with severe intellectual disabilities: Shifting toward person-family interdependent planning. Research \& Practice for Persons with Severe Disabilities, 29, 53-57.

Kohler, P. D. (1996). Taxonomy for transition programming: Linking research and practice. Champaign: Transition Research Institute, University of Illinois at Urbana-Champaign. Martin, J. E., Van Dycke, J. L., Christensen, W. R., Greene, B. A., Gardner, J. E., \& Lovett, D. L. (2006). Increasing student participation in IEP meetings: Establishing the self-directed IEP as an evidenced-based practice. Exceptional Children, 72(3), 299-316. doi:10.1177/001440290607200303 
Miner, C. (2013) Person centered transition planning, in K. Storey \& D. Hunter (Eds.), The road ahead: Transition to adult life for persons with disabilities (pp. 9 -30). Amsterdam, Netherlands: IOS Press

Ministry of Education. (2015). Entering into a section 9 agreement for special education services.

Retrieved from http://www.education.govt.nz/school/student-support/specialeducation/entering-into-a-section-9-agreement-for-special-education-services/

Ministry of Education. (2016). Ongoing resource scheme (ORS). Retrieved from http://www.education.govt.nz/school/student-support/special-education/ors/

Ministry of Health. (2001). New Zealand disability strategy. Wellington, New Zealand: Author.

Mitra, S. (2006). The capability approach and disability. Journal of Disability Policy Studies, 16(4), 236-247. doi: 10.1177/10442073060160040501

Myers, F., Ager, A., Kerr, P., \& Myles, S. (1998). Outside looking in? Studies of the community integration of people with learning disabilities. Disability \& Society, 13(3), 389-413. doi:10.1080/09687599826704

Nussbaum, M. C. (2000). Women and human development: The capabilities approach. Cambridge, England: Cambridge University Press.

Nussbaum, M. C. (2006). Frontiers of justice: Disability, nationality, species membership. Cambridge, MA: Harvard University Press.

NVivo Qualitative Data Analysis Software (Version 10) [Computer software]; QSR International Pty Ltd., 2012.

Office for Disability Issues. (2015, December). Disability Action Plan 2014-2018: Update 2015. Cross-government priorities to improve disabled people's ability to patriciate and contribute to New Zealand. Retrieved from: www.odi.govt.nz/disability-action-plan

Osgood, W., Foster, E.M., Flanagan, C. \& Ruth, R. (2005). On Your Own without a Net: The Transition to Adulthood for Vulnerable Populations. Chicago, IL: University of Chicago Press.

Patton, J.R., \& Dunn, C. (1998). Transition from school to young adulthood. Austin, TX: PRO-ED. Robeyns, I. (2006). Three models of education rights, capabilities, and human capital. Theory and Research in Education, 4(1), 69-84. 
Rusch, F. R., \& Wolfe, P. (2008). When Will Our Values Finally Result in the Creation of New Pathways for Change--Change that We Can Believe In?. Research and Practice for Persons with Severe Disabilities, 33(3), 96-97.

Sen, A. (1985). Well-being, agency and freedom: The Dewey lectures 1984. The Journal of Philosophy, 82(4), 169-221.

Sen, A. (1999). Development as freedom. Oxford, England: Oxford University Press.

Smith, S. R. (2013). Citizenship and disability: Incommensurable lives and well-being. Critical Review of International Social and Political Philosophy, 16(3), 403-420. doi:10.1080/13698230.2013.795708

United Nations Convention on the Rights of Persons with Disabilities and Optional Protocol (A/RES/61/106; 30 March 2007). Retrieved from www.un.org/development/desa/disabilities/convention-on-the-rights-of-persons-withdisabilities.html

Wang, C., \& Burris, M. A. (1997). Photovoice: Concept, methodology, and use for participatory needs assessment. Health Education \& Behavior, 24(3), 369-387.

doi:10.1177/109019819702400309 